Case Report

\title{
Multiple Cutaneous Angiosarcomas after Breast Conserving Surgery and Bilateral Adjuvant Radiotherapy: An Unusual Case and Review of the Literature
}

\author{
Icro Meattini, ${ }^{1}$ Raffaella Santi, ${ }^{2}$ Daniele Scartoni, ${ }^{1}$ Irene Giacomelli, \\ Carla De Luca Cardillo, ${ }^{1}$ Vieri Scotti, ${ }^{1}$ Donato Casella, ${ }^{3}$ Roberta Simoncini, ${ }^{3}$ \\ Lorenzo Orzalesi, ${ }^{3}$ Jacopo Nori, ${ }^{4}$ Milena Paglierani, ${ }^{2}$ and Lorenzo Livi ${ }^{1}$ \\ ${ }^{1}$ Department of Radiation-Oncology, University of Florence, Largo G.A. Brambilla 3, 50134 Florence, Italy \\ ${ }^{2}$ Division of Pathological Anatomy, University of Florence, Largo G.A. Brambilla 3, 50134 Florence, Italy \\ ${ }^{3}$ Department of Surgery, University of Florence, Largo G.A. Brambilla 3, 50134 Florence, Italy \\ ${ }^{4}$ Diagnostic Senology Unit, University of Florence, Largo G.A. Brambilla 3, 50134 Florence, Italy
}

Correspondence should be addressed to Icro Meattini; icro.meattini@unifi.it

Received 7 January 2014; Accepted 2 February 2014; Published 5 March 2014

Academic Editors: S. Aksoy, J. M. Buchanich, and L. Lu

Copyright (C) 2014 Icro Meattini et al. This is an open access article distributed under the Creative Commons Attribution License, which permits unrestricted use, distribution, and reproduction in any medium, provided the original work is properly cited.

\begin{abstract}
Breast angiosarcomas (BAs) are rare but serious events that may arise after radiation exposure. Disease outcome is poor, with high risk of local and distant failure. Recurrences are frequent also after resection with negative margins. The spectrum of vascular proliferations associated with radiotherapy in the setting of breast cancer has expanded, including radiation-associated atypical vascular lesions (AVLs) of the breast skin as a rare, but well-recognized, entity. Although pursuing a benign behavior, AVLs have been regarded as possible precursors of postradiation BAs. We report an unusual case of a 71-year-old woman affected by welldifferentiated bilateral cutaneous BA, diagnosed 1.9 years after adjuvant RT for synchronous bilateral breast cancer. Whole-life clinical followup is of crucial importance in breast cancer patients.
\end{abstract}

\section{Introduction}

Angiosarcomas (ASs) are rare malignant tumors that arise from endothelial cells lining vascular channels $[1,2]$. They account for less than $1 \%$ of all soft tissue sarcomas and occur in all organs of the body. Approximately $8 \%$ of ASs arise in the breast [3]. Primary breast angiosarcomas (BAs) most commonly affect women aged 20 to 40 years without a recognized associated factor [4].

Secondary BAs are usually found in older women at the site of radiotherapy (RT) for breast cancer (BC). They typically involve the dermis and present with skin changes that can easily be misinterpreted even with benign conditions such infection [5].

Neoplastic events attributed to RT in the context of BC are rare. Such occurrences are largely restricted to possible secondary lung and $\mathrm{BC}$, osteosarcomas, malignant fibrous histiocytomas, and fibrosarcomas [5-8].
Postradiation BAs are defined by three characteristics: location in the field of radiation, latency of years after RT, and histologic distinction from the primary neoplasm [9]. The latency period, or interval between RT and the diagnosis of $\mathrm{BA}$, ranges from 3 to 12 years, with most tumors occurring within 6 years after RT [10].

In recent years, the spectrum of vascular proliferations associated with RT in the setting of BC has expanded, including radiation-associated atypical vascular lesions (AVLs) of the breast skin as a rare, but well-recognized, entity $[9,11]$. Since clinic and histologic overlap with well-differentiated BA is likely, AVLs represent a diagnostic and therapeutic challenge. Moreover, although pursuing a benign behavior, AVLs have been regarded as possible precursors of postradiation BAs [12].

We report an unusual case of a 71-year-old woman affected by well-differentiated bilateral cutaneous BAs, 


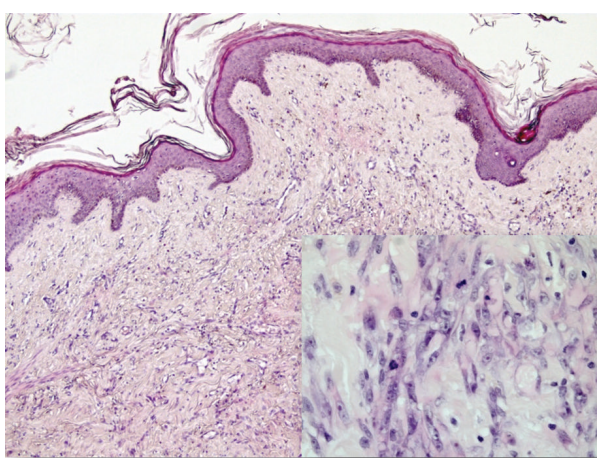

(a)

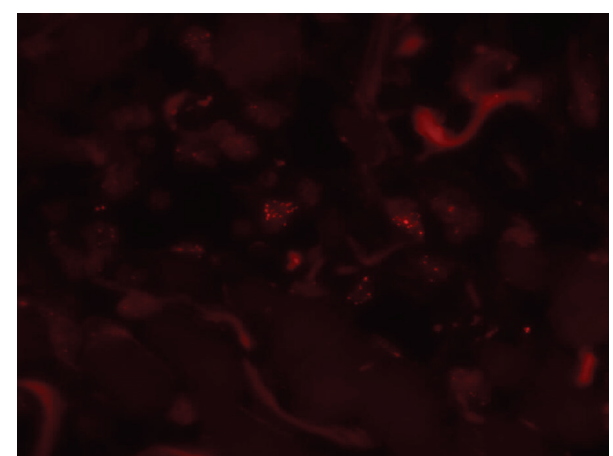

(b)

FIGURE 1: Reexcision of postradiation AVL of the breast skin one month after initial biopsy. Capillary vessels were lined by inconspicuous endothelial cells and randomly arranged throughout the dermis ( (a); H\&E, $\times 10)$. At the periphery of the lesion, a small focus displayed vascular structures with frank cytological atypia and mitotic figures, consistent with well-differentiated post-RT cutaneous BA (inset; H\&E, $\times 40$ ). MYC amplification at FISH analysis strongly supported the diagnosis of AS versus AVL (b). In order to detect copy number abnormalities of MYC oncogene (located at 8q24,12-q24.13), the LSI C-MYC SpectrumOrange Probe (Abbott Molecular Inc., Abbott Park, IL, USA) was used. The fluorescent signals were evaluated under an epifluorescence microscope (DMRD, Leica Mikrosystems Vertrieb GmbH, Germany), using a $\mathrm{HBO} 100 \mathrm{~W}$ mercury arc lamp and the appropriate single band filters (orange and blue) for the two fluorescence signals.

diagnosed 1.9 years after adjuvant RT for synchronous bilateral BC.

\section{Case Report}

In October 2009, due to a swelling in the central superior quadrant of the right breast, discovered by self-palpation, the patient underwent mammography showing a $20 \mathrm{~mm}$ opacity diagnosed as invasive $\mathrm{BC}$ at biopsy. The patient was subjected to wide excision of the lesion, biopsy of two sentinel lymph nodes, and contralateral reconstructive surgery. Histological examination showed a multifocal invasive lobular BC (classic and alveolar type), nuclear grade 2 with pathologic staging pT1cN0. Estrogen receptors and progesterone receptors were positive in $90 \%$ and $70 \%$ of neoplastic cells, respectively; Ki67 proliferative index was $<5 \%$ and HER 2 status was negative.

On the left breast, pathology showed a ductal carcinoma in situ (solid and cribriform type), nuclear grade 2. Estrogen receptors and progesterone receptors were positive in 100\% and $80 \%$ of neoplastic cells, respectively. Postoperative clinicoradiologic staging was negative. Hormonal therapy with letrozole was started.

Both breasts were irradiated. Right breast received a total dose of $60 \mathrm{~Gy}$ ( $50 \mathrm{~Gy}$ on the whole breast plus a boost of $10 \mathrm{~Gy}$ on the tumor bed) and left breast received a total dose of $50 \mathrm{~Gy}$, with conventional fractions of $2 \mathrm{~Gy} /$ day. Computed tomography-based simulation (Big Bore Oncology, Philips, Andover, MA, USA) was performed; a three-dimensional RT planning Pinnacle system (Philips Medical System, Bothell, WA, USA) was used. Both breasts were irradiated with two tangential photon beams while boost was performed with electron beams with energy of $12 \mathrm{MeV}$. Acute side effects were scored according to the Common Toxicity Criteria Adverse Events (CTCAE, version 4). The treatment was well tolerated, with only bilateral breast erythema G1 and asthenia G1.

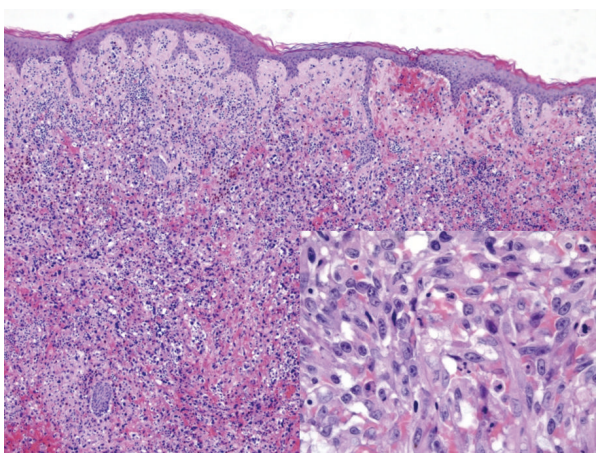

FIGURE 2: Surgical specimen displaying well-differentiated AS which arose in AVL $(\mathrm{H} \& \mathrm{E}, \times 10$; inset, $\mathrm{H} \& \mathrm{E}, \times 40)$.

Regular follow-up visits were performed with annual bilateral mammography and breast ultrasound. In March 2012, at 1.9 years from RT, a small discolored area around the right surgical scar was detected; biopsy showed a radiation-associated AVL. Subsequently, the patient underwent wide excision with histologic diagnosis of cutaneous well-differentiated BA, arising as a small focus on a radiationassociated AVL (Figure 1(a)). Molecular analysis performed by fluorescence in situ hybridization (FISH) demonstrated the presence of MYC [13] amplification (Figure 1(b)). Surgical margins were negative.

On January 2013, at 2.7 years from RT, a lesion appeared on the right breast; therefore patient underwent bilateral mastectomy. The final histology report showed bilateral mild differentiated cutaneous BAs in both breasts, diffusely infiltrating adipose tissue, and dermohypodermic stroma, with bilateral nipple-areola complex involvement (Figure 2).

Patient showed metastatic disease at restaging instrumental tests (multiple lung metastases) and started systemic therapy. At time of writing, 23 months since diagnosis of 


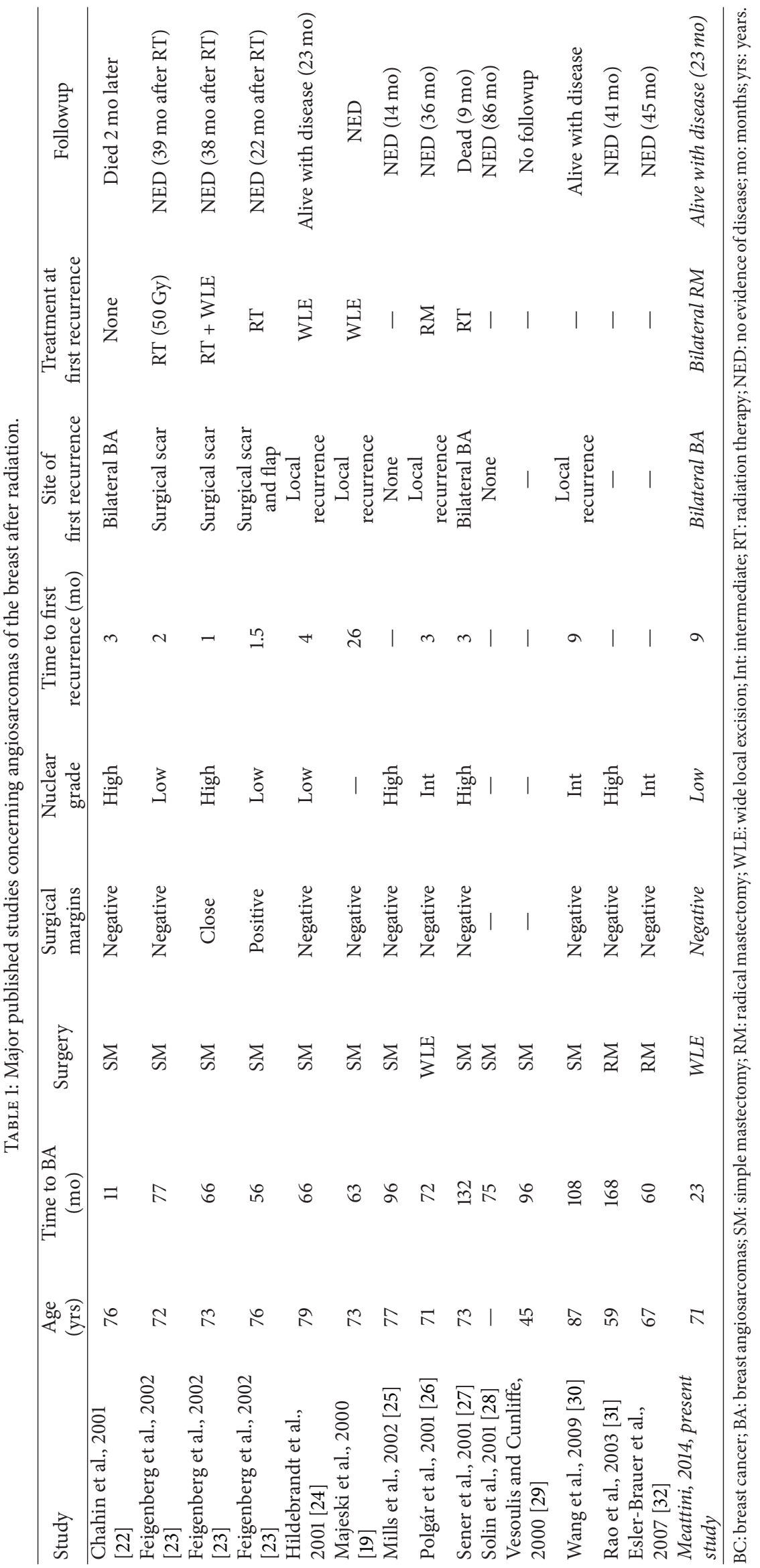


first BA, patient showed partial response to chemotherapy (endovenous docetaxel and gemcitabine, 6 cycles) and started hormonal therapy (letrozole).

\section{Discussion}

The development of malignant tumors after exposure to radiation is a well-recognized event. As a serious complication following therapeutic RT, the development of a sarcoma is a rare event [14]. The first reported case of BA arising within the skin overlying an irradiated breast was published in 1981 [15]. According to a large overview, BAs make up 15\% of RTrelated sarcomas [16].

Despite the apparent correlation between reports of secondary BAs and the increasing use of breast-conserving therapy, a true etiologic effect from RT has been difficult to establish. Although the preserved breast is the most common site of soft tissue sarcoma in patients receiving RT for BC, secondary BAs may also occur out of field [17].

Lymphedema has been implicated as a potential causative factor in the development of BA [18]. It has been suggested that the proliferation of lymphatic channels observed in patients with chronic lymphedema is mediated by growth factors that enhance the process of malignant transformation [4]. Chronic lymphedema may also produce a privileged site with reduced immunologic surveillance $[1,19]$. Furthermore, exposure to RT may compound the risk of malignant transformation by its mutagenic effect and by causing lymphosclerosis, which exacerbates the obstruction associated with lymphadenectomy.

Compared to sporadic BAs, which usually arise in the parenchyma, RT-related BA is usually cutaneous; clinically, it presents as an erythematous plaque, patch, or nodules, often with edema, and evokes a differential diagnosis that includes inflammatory carcinoma or an infectious etiology [20]. Overall the prognosis for patients with RT-associated $\mathrm{BA}$ is poor, with high rates of local and distant recurrence $[9,17]$. Vorburger et al. [21] showed a median disease-free survival (DFS) for patients with primary BAs of 6.5 years and a 5 -year DFS rate of $56 \%$.

Despite the high probability of local disease recurrence, the mainstay of treatment is a simple mastectomy or a wide local excision. A review reported published cases with at least 1 year of followup and showed that around $70 \%$ of patients developed BA recurrences within 1 year from surgery (Table 1). Even with negative margins through radical salvage surgery by simple mastectomy, radical mastectomy, or chest wall resections, additional local tumor recurrences are common [18].

Our unusual case is an example of how skin BAs after RT, although rare, are increasing phenomena. This case differs from the classic postradiation BA presentation reported in the literature. There are no risk factors which may explain this relatively short latency period (1.9 years); there is also no evidence of lymphedema.

Our report emphasizes the difficulty in differentiating well-differentiated BAs from AVLs on both the clinic and histologic findings [14]. Moreover, since AVLs are known to have a shorter interval from RT as compared to AS, postradiation AVL was the expected histological diagnosis. In the context of postradiation, histopathologic characteristics of vascular proliferations should be interpreted with extreme caution. As in this case, anastomosing small vessels exhibiting marked endothelial atypia and the presence of mitotic figures should favor the diagnosis of post-RT well-differentiated AS. In the differential diagnosis between these entities additional help comes from FISH analysis demonstrating MYC amplification, which is present in post-RT ASs but not in AVLs [13].

\section{Conclusions}

Postradiation BAs represent a rare but serious occurrence. Latency between RT and BA diagnosis may vary and may be influenced by several predisposing and treatment factors. Recurrences are frequent also after resection with negative surgical margins. Atypical vascular lesions require careful evaluation to rule out BAs. Clinical and instrumental followup is of crucial importance for these patients.

\section{Conflict of Interests}

The authors declare no conflict of interests.

\section{References}

[1] P. Rosen, "Sarcoma," in Rosen's Breast Pathology, P. P. Rosen, Ed., pp. 813-861, Lippincott Williams \& Wilkins, Philadelphia, Pa, USA, 2001.

[2] J. M. Bardwil, E. E. Mocega, J. J. Butler, and D. J. Russin, "Angiosarcomas of the head and neck region," The American Journal of Surgery, vol. 116, no. 4, pp. 548-553, 1968.

[3] A. L. Folpe and A. M. Gowen, Malignant Vascular Tumors. Soft Tissue Tumors, Mosby, St. Louis, Miss, USA, 1995.

[4] A. F. Nascimento, C. P. Raut, and C. D. M. Fletcher, "Primary angiosarcoma of the breast: clinicopathologic analysis of 49 cases, suggesting that grade is not prognostic," American Journal of Surgical Pathology, vol. 32, no. 12, pp. 1896-1904, 2008.

[5] A. T. Monroe, S. J. Feigenberg, and N. P. Mendenhall, "Angiosarcoma after breast-conserving therapy," Cancer, vol. 97, no. 8, pp. 1832-1840, 2003.

[6] F. Stewart and N. Treves, "Lymphangiosarcoma in post mastectomy lymphedema. A report of six cases in elephantiasis chirurgica," Cancer, vol. 1, pp. 64-81, 1948.

[7] S. C. Pendlebury, M. Bilous, and A. O. Langlands, "Sarcomas following radiation therapy for breast cancer: a report of three cases and a review of the literature," International Journal of Radiation Oncology Biology Physics, vol. 31, no. 2, pp. 405-410, 1995.

[8] I. Meattini, L. Livi, C. Saieva et al., "Breast cancer following Hodgkin's Disease: the experience of the university of florence," Breast Journal, vol. 16, no. 3, pp. 290-296, 2010.

[9] T. Brenn and C. D. Fletcher, "Radiation-associated cutaneous atypical vascular lesions and angiosarcoma: clinicopothologic analysis of 42 cases," American Journal of Surgical Pathology, vol. 29, no. 8, pp. 983-996, 2005.

[10] N. C. Hodgson, C. Bowen-Wells, F. Moffat, D. Franceschi, and E. Avisar, "Angiosarcomas of the breast: a review of 70 cases," 
American Journal of Clinical Oncology, vol. 30, no. 6, pp. 570573, 2007.

[11] U. Flucke, L. Requena, and T. Mentzel, "Radiation-induced vascular lesions of the skin: an overview," Advances in Anatomic Pathology, vol. 20, pp. 407-415, 2013.

[12] R. Santi, V. Cetica, A. Franchi et al., "Tumour suppressor gene TP53 mutations in atypical vascular lesions of breast skin following radiotherapy," Histopathology, vol. 58, no. 3, pp. 455466, 2011.

[13] T. Mentzel, H. U. Schildhaus, G. Palmedo, R. Büttner, and H. Kutzner, "Postradiation cutaneous angiosarcoma after treatment of breast carcinoma is characterized by MYC amplification in contrast to atypical vascular lesions after radiotherapy and control cases: clinicopathological, immunohistochemical and molecular analysis of 66 cases," Modern Pathology, vol. 25, no. 1, pp. 75-85, 2012.

[14] D. M. Parham and C. Fisher, "Angiosarcomas of the breast developing post radiotherapy," Histopathology, vol. 31, no. 2, pp. 189-195, 1997.

[15] J. C. Maddox and H. L. Evans, "Angiosarcoma of skin and soft tissue: a study of forty-four cases," Cancer, vol. 48, no. 8, pp. 1907-1921, 1981.

[16] M. S. Brady, J. J. Gaynor, and M. F. Brennan, "Radiationassociated sarcoma of bone and soft tissue," Archives of Surgery, vol. 127, no. 12, pp. 1379-1385, 1992.

[17] E. A. Morgan, D. E. Kozono, Q. Wang et al., "Cutaneous radiation-associated angiosarcoma of the breast: poor prognosis in a rare secondary malignancy," Annals of Surgical Oncology, vol. 19, pp. 3801-3808, 2012.

[18] A. T. Monroe, S. J. Feigenberg, and N. P. Mendenhall, "Angiosarcoma after breast-conserving therapy," Cancer, vol. 97, no. 8, pp. 1832-1840, 2003.

[19] J. Majeski, R. M. Austin, and R. H. Fitzgerald, "Cutaneous angiosarcoma in an irradiated breast after breast conservation therapy for cancer: association with chronic breast lymphedema," Journal of Surgical Oncology, vol. 74, no. 3, pp. 208212, 2000.

[20] S. D. Billings, J. K. McKenney, A. L. Folpe, M. C. Hardacre, and S. W. Weiss, "Cutaneous angiosarcoma following breastconserving surgery and radiation: an analysis of 27 cases," American Journal of Surgical Pathology, vol. 28, no. 6, pp. 781788, 2004.

[21] S. A. Vorburger, Y. Xing, K. K. Hunt et al., "Angiosarcoma of the breast," Cancer, vol. 104, no. 12, pp. 2682-2688, 2005.

[22] F. Chahin, A. Paramesh, A. Dwivedi et al., "Angiosarcoma of the breast following breast preservation therapy and local radiation therapy for breast cancer," Breast Journal, vol. 7, no. 2, pp. 120123, 2001.

[23] S. J. Feigenberg, N. Price Mendenhall, J. D. Reith, J. R. Ward, and E. M. Copeland III, "Angiosarcoma after breastconserving therapy: experience with hyperfractionated radiotherapy," International Journal of Radiation Oncology Biology Physics, vol. 52, no. 3, pp. 620-626, 2002.

[24] G. Hildebrandt, M. Mittag, U. Gütz, M.-L. Kunze, and U.F. Haustein, "Cutaneous breast angiosarcoma after conserving treatment of breast cancer," European Journal of Dermatology, vol. 11, no. 6, pp. 580-583, 2001.

[25] T. D. Mills, S. J. Vinnicombe, C. A. Wells, and R. Carpenter, "Angiosarcoma of the breast after wide local excision and radiotherapy for breast carcinoma," Clinical Radiology, vol. 57, no. 1, pp. 63-74, 2002.
[26] C. Polgár, Z. Orosz, A. Szerdahelyi et al., "Postirradiation angiosarcoma of the chest wall and breast: issues of radiogenic origin, diagnosis and treatment in two cases," Oncology, vol. 60, no. 1, pp. 31-34, 2001.

[27] S. F. Sener, S. Milos, J. L. Feldman et al., "The spectrum of vascular lesions in the mammary skin, including angiosarcoma, after breast conservation treatment for breast cancer," Journal of the American College of Surgeons, vol. 193, no. 1, pp. 22-28, 2001.

[28] L. J. Solin, A. Fourquet, F. A. Vicini et al., "Salvage treatment for local recurrence after breast-conserving surgery and radiation as initial treatment for mammographically detected ductal carcinoma in situ of the breast," Cancer, vol. 91, no. 6, pp. 10901097, 2001.

[29] Z. Vesoulis and C. Cunliffe, "Fine-needle aspiration biopsy of postradiation epithelioid angiosarcoma of breast," Diagnostic Cytopathology, vol. 22, no. 3, pp. 172-175, 2000.

[30] X. Y. Wang, J. Jakowski, O. W. Tawfik, P. A. Thomas, and F. Fan, "Angiosarcoma of the breast: a clinicopathologic analysis of cases from the last 10 years," Annals of Diagnostic Pathology, vol. 13, no. 3, pp. 147-150, 2009.

[31] J. Rao, J. G. DeKoven, J. D. Beatty, and G. Jones, "Cutaneous angiosarcoma as a delayed complication of radiation therapy for carcinoma of the breast," Journal of the American Academy of Dermatology, vol. 49, no. 3, pp. 532-538, 2003.

[32] L. Esler-Brauer, W. Jaggernauth, and N. C. Zeitouni, "Angiosarcoma developing after conservative treatment for breast carcinoma: case report with review of the current literature," Dermatologic Surgery, vol. 33, no. 6, pp. 749-755, 2007. 


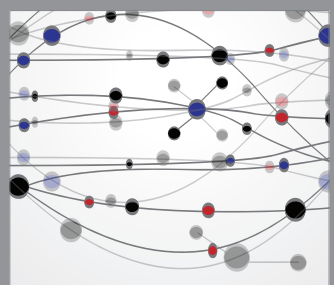

The Scientific World Journal
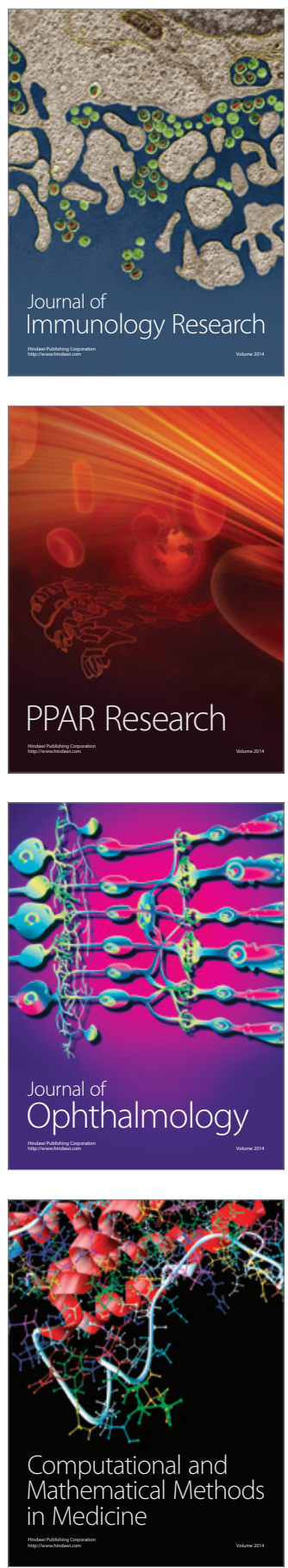

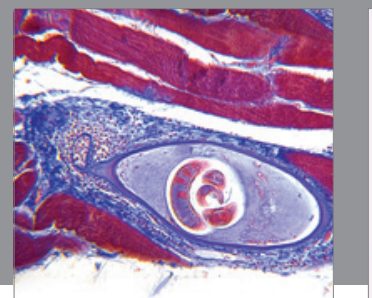

Gastroenterology

Research and Practice
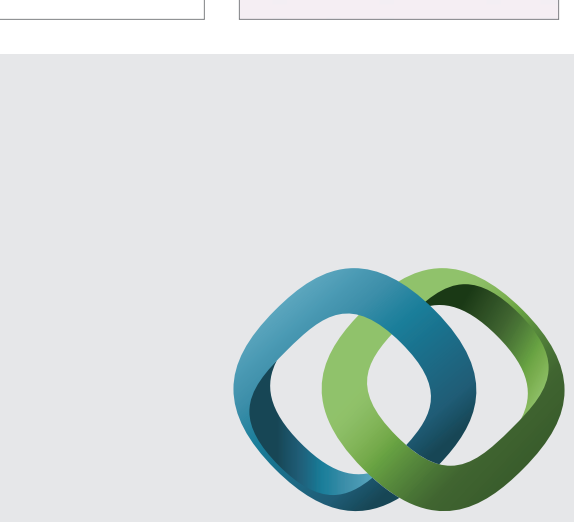

\section{Hindawi}

Submit your manuscripts at

http://www.hindawi.com
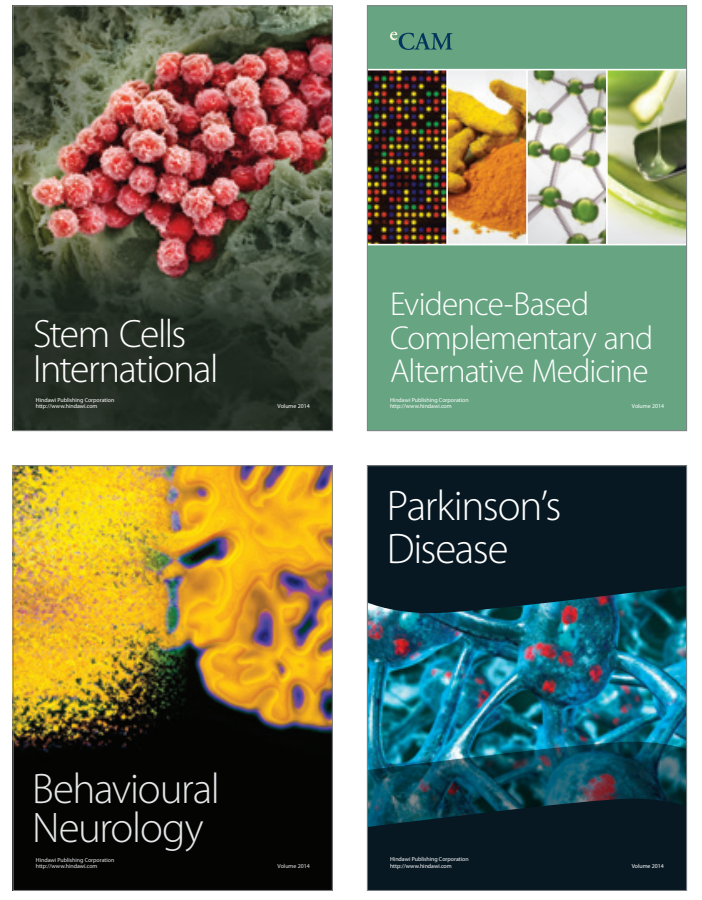
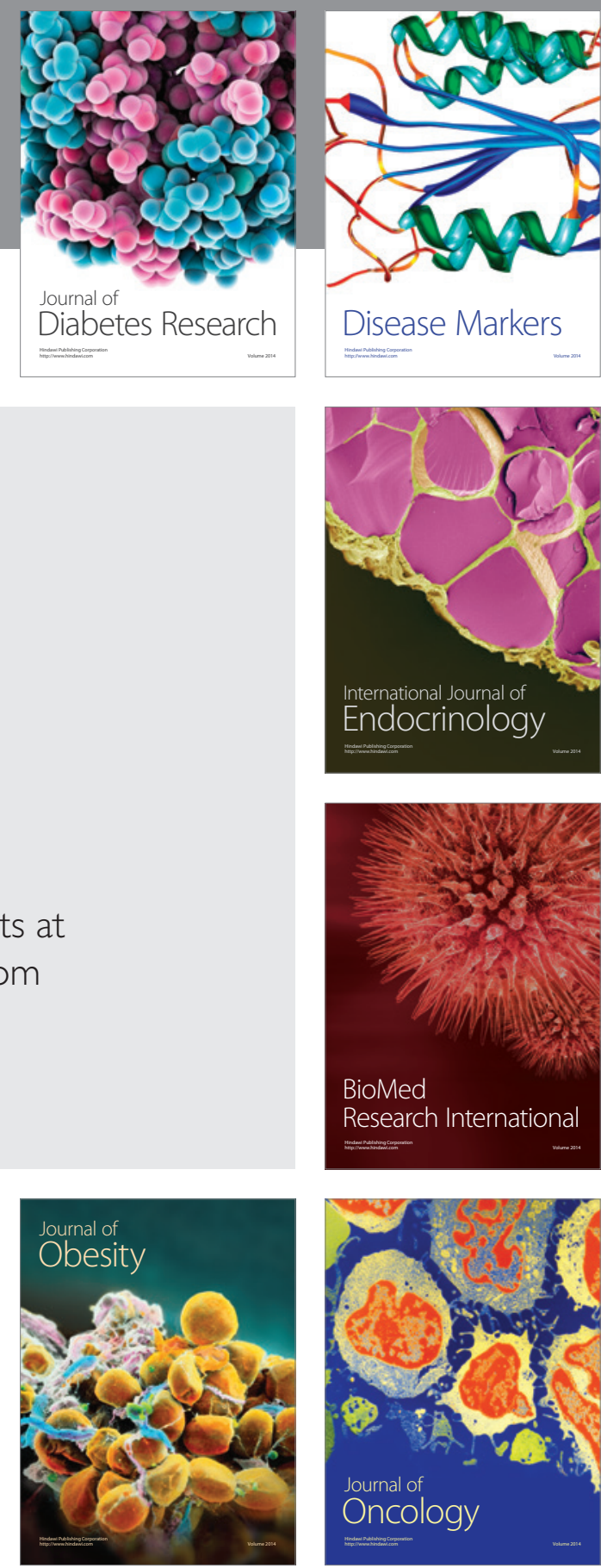

Disease Markers
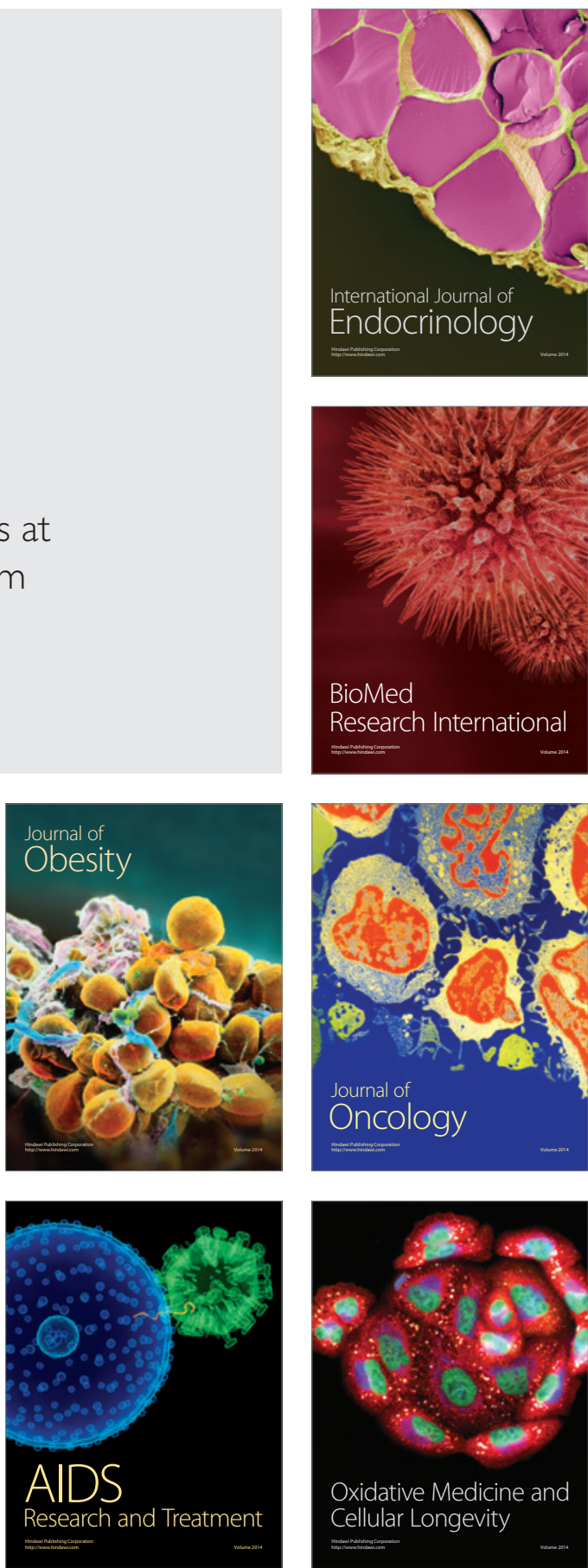